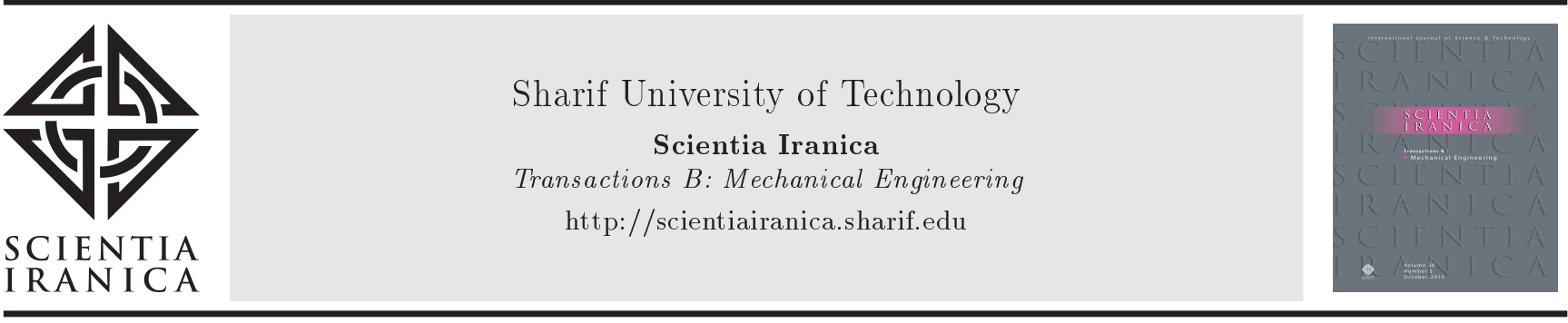

\title{
Powder metallurgy Mg-Sn alloys: Production and characterization
}

\author{
Ö. Özgün ${ }^{\mathrm{a}, *}$, K. Aslantaş ${ }^{\mathrm{b}}$, and A. Erçetin ${ }^{\mathrm{a}}$ \\ a. Department of Mechanical Engineering, Bingol University, Bingol, 12000, Turkey. \\ b. Department of Mechanical Engineering, Afyon Kocatepe University, Afyonkarahisar, 03200, Turkey.
}

Received 7 January 2018; accepted 13 May 2019

\section{KEYWORDS}

$\mathrm{Mg}-\mathrm{Sn}$ alloys;

Powder metallurgy;

Microstructure;

Mechanical properties.

\begin{abstract}
In this study, $\mathrm{Mg}-\mathrm{Sn}$ alloys were produced with the addition of Sn to $\mathrm{Mg}$ powder at different ratios through the Powder Metallurgy $(\mathrm{P} / \mathrm{M})$ method. A new mixing technique was used in the production to avoid the disadvantages of high reactivity specific to $\mathrm{Mg}$ powders. The prepared powder mixtures were turned into components by processing through hot pressing. The produced components were characterized by density measurements, microstructure examinations, and mechanical tests. The density measurements were made according to the Archimedes principle. The microstructural characterization was performed by X-Ray Diffraction (XRD) analysis, Scanning Electron Microscope (SEM) investigations, and Energy Dispersive Spectrometry (EDS) analyses. The hardness measurements and tensile tests were used for determining mechanical properties. Densities close to the theoretical density were obtained in the produced parts. XRD and SEM investigations showed that the components produced were composed of $\alpha-\mathrm{Mg}$ and $\mathrm{Mg}_{2} \mathrm{Sn}$ phases of the microstructure consisting of coaxial grains. The rising $\mathrm{Sn}$ content increased the amount of discrete $\mathrm{Mg}_{2} \mathrm{Sn}$ precipitates at grain boundaries, thereby ensuring higher hardness and strength values.
\end{abstract}

(C) 2020 Sharif University of Technology. All rights reserved.

\section{Introduction}

$\mathrm{Mg}$ is one of the most plentiful elements in nature and forms $2.7 \%$ of the earth's crust $[1,2] . \quad \mathrm{Mg}$ is the lightest structural metal with a density value of $1.74 \mathrm{~g} / \mathrm{cm}^{3}$ [3-8] and enjoys superior properties such as high strength/weight ratio, excellent ability for vibration damping, good workability, high thermal conductivity, easy recyclability, and high dimensional stability $[2,9,10]$. These properties make $\mathrm{Mg}$ one of the most promising materials for many applications [1113] such as automotive parts, computer components,

\footnotetext{
*. Corresponding author. Tel.: +90 4262160012/2385 Fax: +90 4262160034

E-mail address: oozgun@bingol.edu.tr (Ö. Özgün)
}

mobile phones, space and aeronautics applications, military equipment, biomedical applications, home and office hardware, sporting goods, and hand tools [14]. Despite its superior properties, the disadvantages of $\mathrm{Mg}$ such as low corrosion resistance, low malleability, low mechanical properties, high shrinkage rate during solidification, and high chemical reactivity limit its applications $[7,15]$.

Today, the most widely used process in producing parts from $\mathrm{Mg}$ alloys is casting [16]. Although $98 \%$ of the $\mathrm{Mg}$ parts are produced by casting techniques [17], the number of $\mathrm{Mg}$ alloys used in casting applications is very limited. Under such circumstances, in addition to the fact that there are important optimizations to be made on the existing $\mathrm{Mg}$ alloys, new $\mathrm{Mg}$ alloys with high strength can also be discovered [18]. Much of the research on $\mathrm{Mg}$ alloys has focused on the development of alloys suitable for casting techniques 
in terms of low production costs [19]. However, there are some difficulties encountered in producing $\mathrm{Mg}$ alloys by casting techniques. The molten $\mathrm{Mg}$ tends to be oxidized and burnt [17]; therefore, some particular precautions must be taken regarding the equipment used to produce $\mathrm{Mg}$ alloys by the casting method [20]. However, the production of $\mathrm{Mg}$ alloys by casting methods also introduces some undesirable structural characteristics that may adversely affect performance in service conditions. Above all, the materials obtained by melting and casting techniques contain microstructural inhomogeneities and have a large grain size, causing low strength [21]. Mg alloys exhibit a broad range of solidification. Therefore, these alloys are highly susceptible to a number of casting defects including segregation, porosity, and hot tearing $[22,23]$. There are also restrictions on the geometry of the components in production by casting methods. For example, AZ series Mg alloys, which are cheaper than other Mg alloys, are usually turned into parts by highpressure casting [16]. However, despite their good pourability, it is not always possible, or economically feasible, to cast complex shaped parts [24]. One of the important features of these alloys is that they can be produced only in long and thin sections with high-pressure casting; this geometry limits the use of these alloys to applications such as dashboard, steering wheel, and seat frames [16].

The ability of $\mathrm{Mg}$ to be shaped at low room temperature makes it necessary to always produce parts at high temperatures by plastic deformation processes from $\mathrm{Mg}$ alloys [25]. This situation leads to higher production costs [25]. The most important obstacle in the development of the market for $\mathrm{Mg}$ alloys produced by plastic deformation methods is the low production speed. Extrusion of a typical $\mathrm{Mg}$ alloy has to be done 5-10 times slower than the typical Al alloy. The basis of this problem is the fact that the temperature range in which the material can be shaped without melting and hot tearing is too limited for conventional extrusion alloys of $\mathrm{Mg}$ [26]. On the other hand, at low temperatures, cold crack formation occurs due to the low ductility of $\mathrm{Mg}$ [25].

While the inadequate material properties are effective in decreasing the utilization rate of $\mathrm{Mg}$ alloys in engineering applications, especially in the automotive industry, the biggest obstacle remains the production costs, being very high [27]. The costs of $\mathrm{Mg}$ and its alloys are reasonable, and the development of their properties will promote their prevalent use. However, an increase in knowledge of the production processes of $\mathrm{Mg}$ alloys will lead to an increase in the use of $\mathrm{Mg}$ alloys as automotive components [28]. Conventional methods have to be further developed to achieve a finegrained size and a homogeneous microstructure [29]. More importantly, the development of production pro- cesses representing an alternative to existing production methods is becoming very important [20].

Powder Metallurgy $(\mathrm{P} / \mathrm{M})$ is the most costeffective one of all other production techniques possible in the production of any part [30], providing metallic parts to be produced such that their microstructures are homogeneous and finely grained [31]. The failure of materials produced by melting in service conditions usually results from low or inhomogeneous properties and segregation, causing the thermomechanical properties to decrease [32]. The $\mathrm{P} / \mathrm{M}$ allows for the production of high-enduring parts whose properties exhibit a superior and homogeneous distribution, overcoming the difficulties that result from defects related to melting [33]. Most importantly, $\mathrm{P} / \mathrm{M}$ enhances the flexibility of the alloy system $[31,34]$ by enabling the use of strategic elements [35]. Thus, P/M makes it possible to produce parts from alloy systems with chemical compositions that cannot possibly be combined with other production methods [36,37]. This feature can also facilitate the development of the new $\mathrm{Mg}$ alloy systems needed and enable the production of existing $\mathrm{Mg}$ alloys with superior properties. However, although $\mathrm{P} / \mathrm{M}$ has the advantages listed above, it involves some difficulties in the production of $\mathrm{Mg}$ alloys. $\mathrm{Mg}$ powders characterized by high reactivity and fast ignition properties lie behind the basis of these difficulties [38]. The aforementioned properties of $\mathrm{Mg}$ powders make it necessary to completely cut off the contact between the powders and oxygen in the production of parts by $\mathrm{P} / \mathrm{M}$ technique. For this reason, not only the sintering process but also the weighing, mixing, mold filling, and press shaping of powders must also be done in a protective gas environment [39]. The mixing process, which is particularly effective in the success of the $\mathrm{P} / \mathrm{M}$ process and in the final properties of the part to be produced, must be well controlled due to the high reactivity of $\mathrm{Mg}$ powders. The mechanical alloying technique is widely used for mixing powders in $\mathrm{P} / \mathrm{M}$. However, the very low ignition temperature of $\mathrm{Mg}$ powder causes the ball mixing process to be unsafe [37]. The above difficulties have made the $\mathrm{P} / \mathrm{M}$ method a difficult process for producing parts from $\mathrm{Mg}$ alloys [38], which is the reason for its rare usage up until now. However, in recent times, studies on the production of magnesium alloys by $\mathrm{P} / \mathrm{M}$ techniques were carried out [40-42].

In this study, $\mathrm{Mg}$ alloys were produced by the $\mathrm{P} / \mathrm{M}$ method through the addition of $\mathrm{Sn}$ at different ratios to $\mathrm{Mg}$ powder. A new mixing technique was used in production to avoid disadvantages such as high reactivity specific to $\mathrm{Mg}$ powders. The powder mixes prepared by the new mixing technique were turned into components by a hot pressing process. The produced components were characterized by density measurements, microstructure studies, and mechanical 
tests. The results obtained from the characterization process were compared with the properties of similar $\mathrm{Mg}$ alloys, produced by other production methods in the literature.

\section{Material and method}

$\mathrm{Mg}$ powder used in this study has a particle size less than $100 \mu \mathrm{m}$ and purity of $99.5 \%$. In Figure 1, Scanning Electron Microscope (SEM) images taken of the powders, used in the study, are given. The tin powder used is obtained from Sigma Aldrich firm and has a purity rate of $99 \%$ and a particle size of $10 \mu \mathrm{m}$. Three different Mg-Sn alloys were produced in the study based on the $\mathrm{Mg}-\mathrm{Sn}$ phase diagram. These alloys are designed to contain 5 wt.\%, 9 wt.\%, and 13 wt.\% Sn. The mixing of the powders was carried out with a different technique based on the idea of cutting off Mg's contact with air. In this mixing technique, $\mathrm{Mg}$ powder was ensured to be coated with paraffin dissolved in a volatile substance (hexane) that did not involve oxygen in its formula in order to cut off the contact with oxygen. A specifically prepared vertical
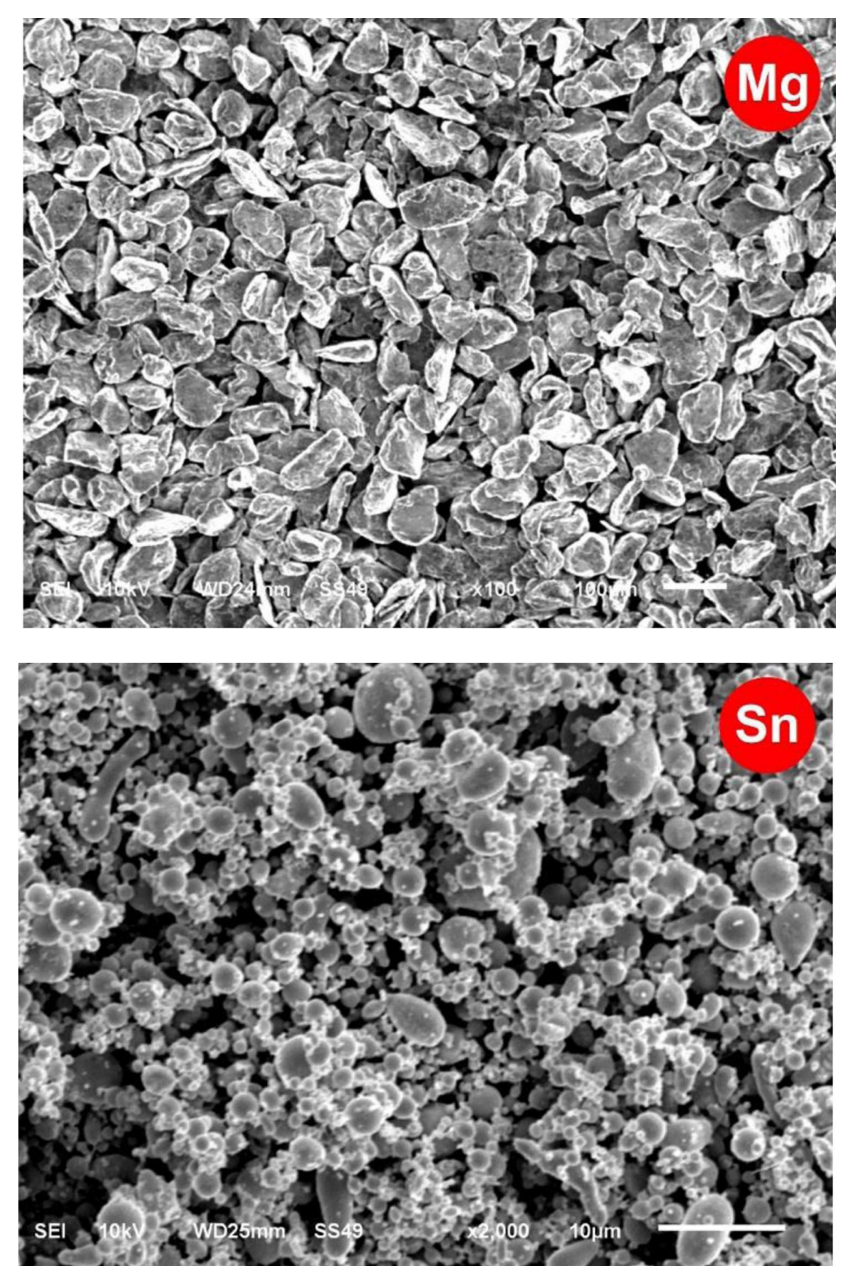

Figure 1. SEM images of the powders used in the study. mixer with vanes was used for this process. Then, $200 \mathrm{ml}$ of hexane and paraffin wax by as much as $20 \%$ of the whole volume of $\mathrm{Mg}$ powder was inserted into a beaker and placed on a plate heated up to $60^{\circ} \mathrm{C}$ (above the melting point of paraffin wax) until the paraffin wax melted. Then, the $\mathrm{Mg}$ powder with a certain package weight (100 gr) was poured into the beaker as soon as its package was opened to prevent its contact with air. The temperature of the hot plate was raised above the boiling temperature of the hexane $\left(100^{\circ} \mathrm{C}\right)$ and mixed up until the whole hexane evaporated. After the evaporation of hexane, the remainder was the $\mathrm{Mg}$ powder covered with paraffin wax. This powder was divided into 3 parts to which Sn was added until the aforementioned ratios were obtained; then, it was placed into an Erlenmeyer flask. Next, 150 cc of hexane was added to the Erlenmeyer, and the mixture was stirred again on the hot plate heated to $100^{\circ} \mathrm{C}$ until all the hexane evaporated. The mixer was designed such that height adjustment could be made and that the propeller might be folded so that it could fit through the narrow mouth of the Erlenmeyer. The propeller of the mixer was adjusted to be as close as possible to the bottom of the Erlenmeyer when mixing. Thus, $\mathrm{Mg}$ and $\mathrm{Sn}$ powder particles were continuously kept moving in the hexane-paraffin wax solution during the mixing process, and they were kept hanging to prevent settling until the whole hexane evaporated. After the complete evaporation of hexane, a homogeneous mixture of powder covered with paraffin remained.

The obtained mixtures were subjected to hot pressing with the application of $30 \mathrm{MPa}$ pressure at $600^{\circ} \mathrm{C}$ in a vacuum environment using a graphite mold with a sintering machine (procured from Zheng Zhou Golden Highway Co., LTD). It took three minutes to reach the sintering temperature of the device, and the samples were kept at this temperature for 15 minutes. The densities of the produced samples were measured according to Archimedes' principle. The X-Ray Diffraction (XRD) analysis was carried out on a Rigaku Ultima IV X-ray diffractometer device using a $\mathrm{Cu}$ X-ray tube $(\lambda=1.5405)$ at a scanning rate of $0.02 / 0.4$ degree/sec. The SEM and SEM/EDS studies were performed with a JEOL JSM 6510 SEM and an IXRF 550 brand EDS system connected to this device. To carry out SEM examinations, the samples passed through the metallographic preparation stages and, then, were etched with $95 \%$ ethyl alcohol $+5 \% \mathrm{HNO}_{3}$ solution. The hardness measurements were performed with a Wilson Hardness device using a load of $100 \mathrm{~g}$. The tensile tests were carried out at a constant speed of $1 \mathrm{~mm} / \mathrm{min}$ using a Shimadzu AG-IC $50 \mathrm{kN}$ model device. The used tensile specimens were prepared according to the ASTM: E8/E8M-11 Standard. The 
tensile tests were applied to 4 samples for each alloy group.

\section{Results and discussion}

Figure 2 shows the patterns obtained from the components produced as a result of XRD analysis. Only peaks belonging to $\alpha-\mathrm{Mg}$ and $\mathrm{Mg}_{2} \mathrm{Sn}$ phases were present in the obtained patterns. With an increase in $\mathrm{Sn}$ ratio, the intensity of $\alpha-\mathrm{Mg}$ peaks decreased, while the intensity of the $\mathrm{Mg}_{2} \mathrm{Sn}$ intermetallic peaks increased. A similar finding was also obtained in a study conducted by Liu et al. [43]. Further to that, it was reported that MgSn alloys, characterized by different Sn contents and produced by the casting technique, had only peaks of $\alpha-\mathrm{Mg}$ and $\mathrm{Mg}_{2} \mathrm{Sn}$ phases in the XRD patterns and that the $\mathrm{Mg}_{2} \mathrm{Sn}$ peak intensity increased with the increasing $\mathrm{Sn}$ ratio [43]. The XRD analysis results were also consistent with the Mg-Sn binary phase diagram. The examination of the phase diagram [44] showed that Sn had almost zero solubility in $\mathrm{Mg}$ at room temperature, and the microstructure could be formed by $\mathrm{Mg}$ and $\mathrm{Mg}_{2} \mathrm{Sn}$ phases based on the ratios used in the present study.

The SEM images taken of the components with different magnifications are given in Figure 3. According to the SEM images taken at small magnifications, the applied production parameters allowed obtaining a highly dense microstructure that did not contain pores. According to the SEM images taken at high magnifications, white precipitates formed at grain boundaries. Through XRD analysis, only two phases were found in all samples: $\alpha-\mathrm{Mg}$ and $\mathrm{Mg}_{2} \mathrm{Sn}$. Based on this finding, it can be said that the white precipitates seen on the grain boundaries are the precipitates that belong to the $\mathrm{Mg}_{2} \mathrm{Sn}$ phase. Liu et al. [43] reported that in the $\mathrm{Mg}$-Sn alloys produced by casting, Sn atoms whose solubility rapidly reduced with a decrease in temperature during solidification

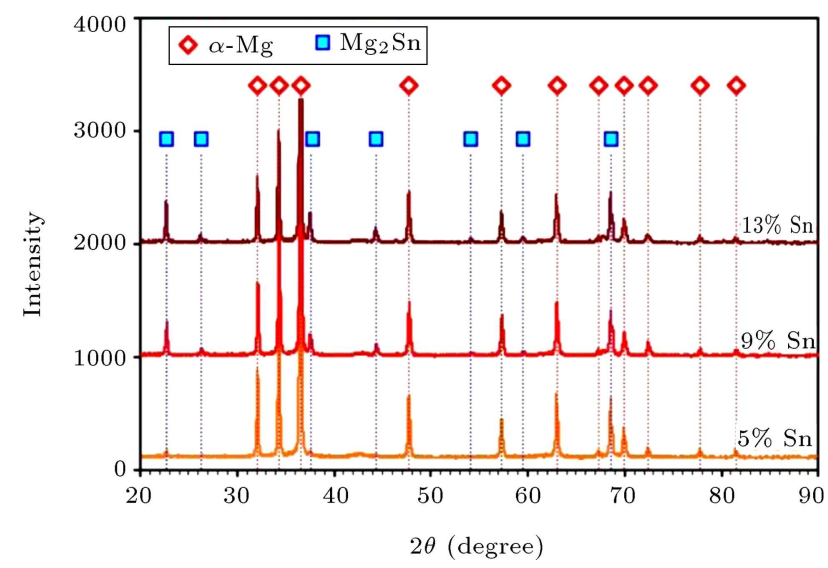

Figure 2. Patterns of the produced alloys obtained from the XRD analysis. formed $\mathrm{Mg}_{2} \mathrm{Sn}$ precipitates. In the present study, the hot pressing process was implemented at $600^{\circ} \mathrm{C}$. According to the $\mathrm{Mg}$-Sn phase diagram [43], all $\mathrm{Sn}$ components can dissolve in $\mathrm{Mg}$ at the temperature of the hot pressing process. For this reason, $\mathrm{Mg}_{2} \mathrm{Sn}$ precipitates are considered to be forming during the cooling stage after the hot pressing process, because, as Liu et al. [43] noted, while the solubility of Sn atoms in $\mathrm{Mg}$ reduces as the temperature decreases, the atoms must be separated from $\mathrm{Mg}$ by forming a new phase. The SEM images showed that $\mathrm{Mg}_{2} \mathrm{Sn}$ precipitates formed, especially at grain boundaries. This situation is attributed to the diffusion that easily occurs at grain boundaries. All SEM images showed that a finer grain microstructure was obtained with the increasing Sn ratio. Cheng et al. [45] reported that a finer grain microstructure was obtained with increasing $\mathrm{Mg}_{2} \mathrm{Sn}$ volume ratio in $\mathrm{Mg}-\mathrm{Sn}$ alloys with Sn content at different proportions, produced by the casting method. This condition is attributed to $\mathrm{Mg}_{2} \mathrm{Sn}$ particles that act as barriers to grain coarsening [45]. Similar findings were also found in the studies of Liu et al. [43]. There are similar explanations in different alloy systems in the literature. For example, hard phases forming at grain boundaries in superalloys have been reported to be impressively inhibiting the grain growth $[33,46-$ 49]. In the present study, a higher amount of $\mathrm{Mg}_{2} \mathrm{Sn}$ precipitate formed with increasing $\mathrm{Sn}$ ratio, resulting in a finer grain microstructure. The increasing Sn ratio leads to not only the formation of a higher $\mathrm{Mg}_{2} \mathrm{Sn}$ precipitate, but also the formation of larger $\mathrm{Mg}_{2} \mathrm{Sn}$ precipitates. A similar finding was also found in $\mathrm{Mg}$ Sn alloys produced by the casting method. Liu et al. [43] found that the increasing Sn ratio resulted in larger $\mathrm{Mg}_{2} \mathrm{Sn}$ precipitates as an increase in the amount of solute led to phase coarsening. Another advantage of increasing the $\mathrm{Sn}$ ratio and reducing the grain size by allowing the formation of larger $\mathrm{Mg}_{2} \mathrm{Sn}$ precipitates in larger amounts in the present study is a reduction in the gap between the sizes of the $\alpha$-Mg grains in the microstructure. In particular, in the SEM image of the sample with $5 \% \mathrm{Sn}$, the difference between its dimensions was very large, whereas this difference significantly reduced in the sample with $13 \% \mathrm{Sn}$.

ASTM grain size numbers of the produced samples were calculated as follows: 5 in the sample containing $5 \% \mathrm{Sn}, 5.5$ in the sample containing $9 \%$ $\mathrm{Sn}$, and 6 in the sample containing $13 \% \mathrm{Sn}$. These ASTM grain size numbers correspond to 56.6, 47.6, and $40 \mu \mathrm{m}$, respectively. In the previous study, it was reported that the grain size of the material containing $7.12 \%$ Sn produced with casting was about $115 \mu \mathrm{m}$ [50]. After applying the homogenization process to this material at a temperature of $390^{\circ} \mathrm{C}$ for 320 minutes, the grain size was reported to rise to $138 \mu \mathrm{m}$. In another study, Chen et al. [51] reported that in samples 

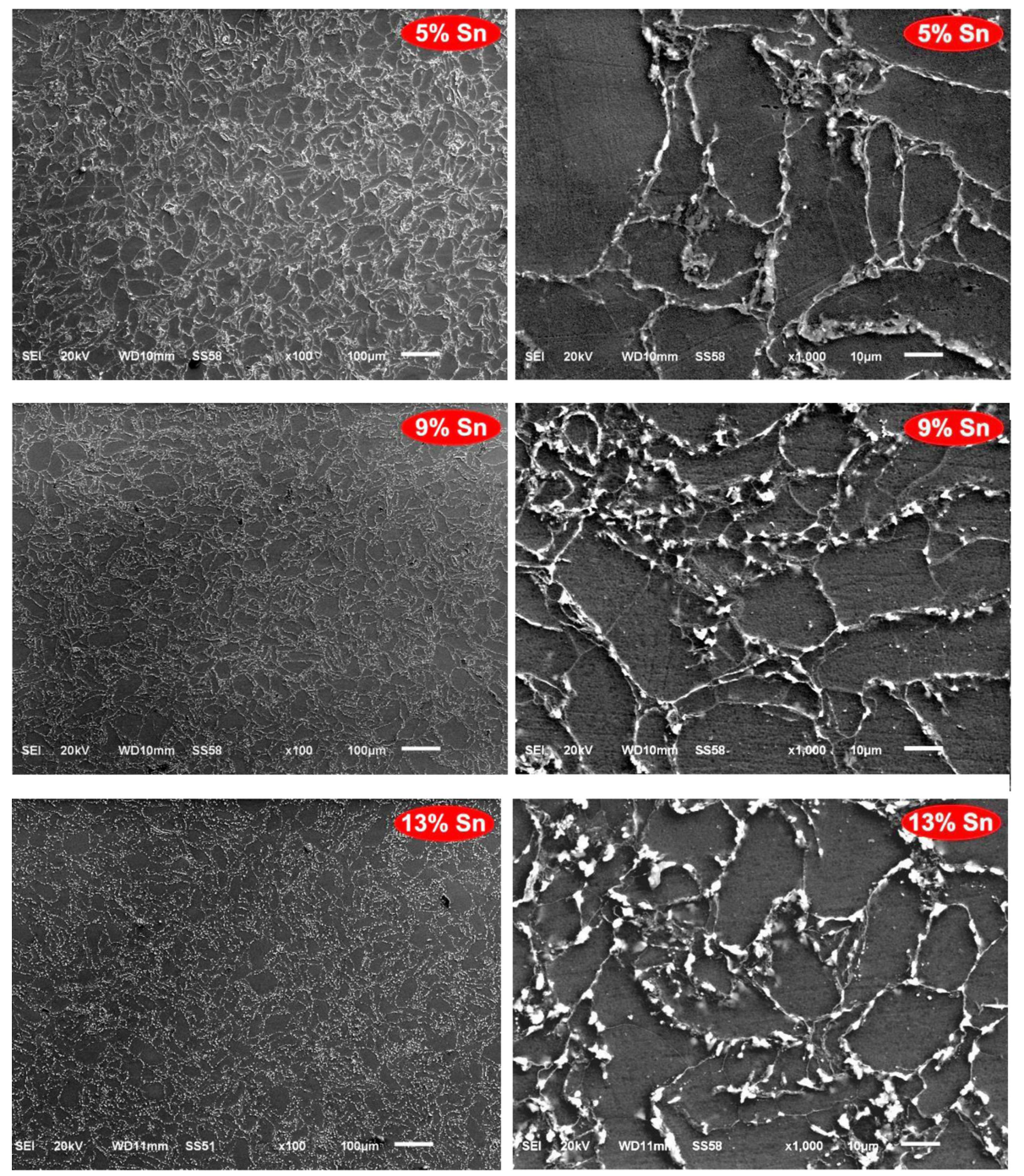

Figure 3. SEM images of Mg-Sn alloys taken at different magnifications.

with $3 \%, 7 \%$, and $14 \% \mathrm{Sn}$, to which they applied a homogenization process at $480^{\circ} \mathrm{C}$ for 12 hours to produce by casting and to perform extrusion process, the grain sizes were 220,160 , and $93 \mu \mathrm{m}$, respectively. The above explanations were given about the effect of increasing $\mathrm{Sn}$ ratio on grain size refinement. In the present study, it was observed that even the sample containing $5 \%$ Sn produced by the $\mathrm{P} / \mathrm{M}$ method had a finer grain size (about half) than the material with higher Sn contents produced by the casting method. It is known that the finer grain size is the reason for the material to possess superior mechanical properties under low-temperature service conditions [46-48,52]. In the particular case of $\mathrm{Mg}$ alloys, the effect of grain size on strength is more pronounced than that in $\mathrm{Al}$ alloys [51]. Accordingly, it can be mentioned that the samples produced by the $\mathrm{P} / \mathrm{M}$ method are superior to the similar alloys produced by casting in terms of grain size and mechanical properties in the present study. It has been reported that $\mathrm{Mg}$ alloys produced by casting are composed of dendritic grains [43]. Another advantage of the $\mathrm{P} / \mathrm{M}$ method is that it provides a microstructure consisting of coaxial grains.

Figure 4 shows the images of SEM elemental mapping analysis taken from a sample containing $13 \% \mathrm{Sn}$. It is seen that the $\mathrm{Sn}$ ratio exhibits a significant increase, while the $\mathrm{Mg}$ ratio decreases in the precipitates forming at the grain boundaries, compared to the matrix. Considering the XRD analysis results and according to the explanations given about the analyzed SEM, these precipitates were $\mathrm{Mg}_{2} \mathrm{Sn}$ precipitates. The role of the phases in the material in relation to the material properties is determined by the shape and distribution of these phases [43]. In the previous study [50], it was determined that the cast $\mathrm{Mg}$-Sn alloy formed the $\mathrm{Mg}_{2} \mathrm{Sn}$ phase as a continuous network at grain boundaries. In another study, Liu et al. [43] reported that the tendency of the $\mathrm{Mg}_{2} \mathrm{Sn}$ phase with the increasing Sn content to form a semi-continuous network at grain boundaries increased. These large 


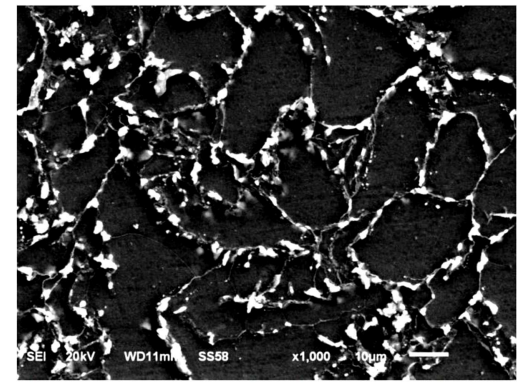

$\mathrm{Mg}$
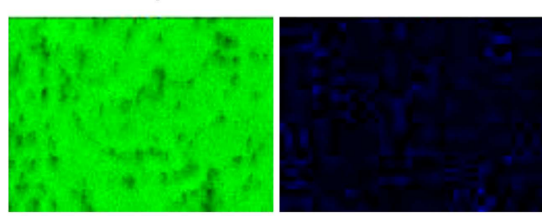

Figure 4. Images of SEM elemental mapping analysis taken from the sample with $13 \%$ Sn.

intermetallic phases and the semi-continuous network morphology reportedly affected strength and ductility adversely by accelerating crack formation and progression [43]. It has been reported that the precipitates in materials formed as discrete particles instead of those formed as a continuous film at grain boundaries would increase strength by preventing grain boundary sliding $[32,48,53,54]$. In accordance with this general rule, Liu et al. showed that discrete $\mathrm{Mg}_{2} \mathrm{Sn}$ precipitates formed at grain boundaries of $\mathrm{Mg}$-Sn alloys increased strength by preventing dislocation movements [43]. According to the images of the SEM elemental mapping analysis in the present study, it is clearly seen that the $\mathrm{Mg}_{2} \mathrm{Sn}$ precipitates are formed as discrete particles unconnected to each other. This is important in terms of the mechanical properties of the material. According to the above explanations, the microstructure obtained by $\mathrm{P} / \mathrm{M}$ in the present study is superior to the casting method in terms of strength, as expected.

Liu et al. [43] also reported the formation of very small secondary $\mathrm{Mg}_{2} \mathrm{Sn}$ precipitates inside the grains. In the present study, it is seen that in the image showing the distribution of $\mathrm{Sn}$, the amount of Sn shows a significant increase in precipitates; however, $\mathrm{Sn}$ is also present inside the grains. According to the patterns obtained from the XRD analysis in the present study and the formation of the secondary $\mathrm{Mg}_{2} \mathrm{Sn}$ precipitates indicated by Liu et al. [43], it can be concluded that $\mathrm{Sn}$ inside the grains formed very small $\mathrm{Mg}_{2} \mathrm{Sn}$ precipitates. From the image showing the distribution of the oxygen element, an increase in the amount of oxygen at points where the $\mathrm{Mg}_{2} \mathrm{Sn}$ precipitates exist draws the attention. It is clear that the $\mathrm{Mg}_{2} \mathrm{Sn}$ phase is oxidized in significant amounts. Another result that can be extracted from the images of SEM elemental mapping analysis is that the new mixing technique used in this study is successful. Both $\mathrm{Mg}$ and Sn elements exhibit a homogeneous distribution throughout the microstructure. In the SEM images taken at small magnification shown in Figure 3, the fact that $\mathrm{Mg}_{2} \mathrm{Sn}$ precipitates formed as discrete particles at all grain boundaries in the microstructure supports this thought.

Given in Figure 5 are the density values of the produced materials determined by the Archimedes principle and the relative density values obtained by dividing these density values by the theoretical densities calculated according to the rule of mixture. Along with the increasing Sn ratio, the densities of the produced components also increased naturally. Average density values according to the increasing Sn ratio were measured as 1.803, 1.861, and 1.898 g.cm ${ }^{-3}$, which are very close to the theoretical density values. The average relative density values obtained by dividing these values by the theoretical densities were $99.83 \%$, $99.78 \%$, and $98.9 \%$, respectively. The SEM images shown in Figure 3, which appear to have almost no pores, also support these values. Turan et al. [55] reported that a relative density rate of $99.76 \%$ was reached in pure $\mathrm{Mg}$ parts, produced in the hot pressing process. $\mathrm{Mg}$ alloys exhibit a broad solidification range. For this reason, these alloys are highly susceptible to a range of casting errors, where porosity is also important $[22,23]$. The fact that $\mathrm{Mg}$-Sn alloys reached relative density values very close to the theoretical density by the hot pressing process both in the study of Turan et al. [55] and in the present study shows that the $\mathrm{P} / \mathrm{M}$ is a promising production method for producing $\mathrm{Mg}$ alloys. Although relative density values close to the theoretical density were reached in all samples, it was observed that, against the expectations, there was a slight decrease in the obtained relative density values with increasing Sn ratio.

The hardness values of the produced components are given in Figure 6. It is seen that the increasing $\mathrm{Sn}$ addition increases the obtained hardness values and the highest hardness is reached in the sample with

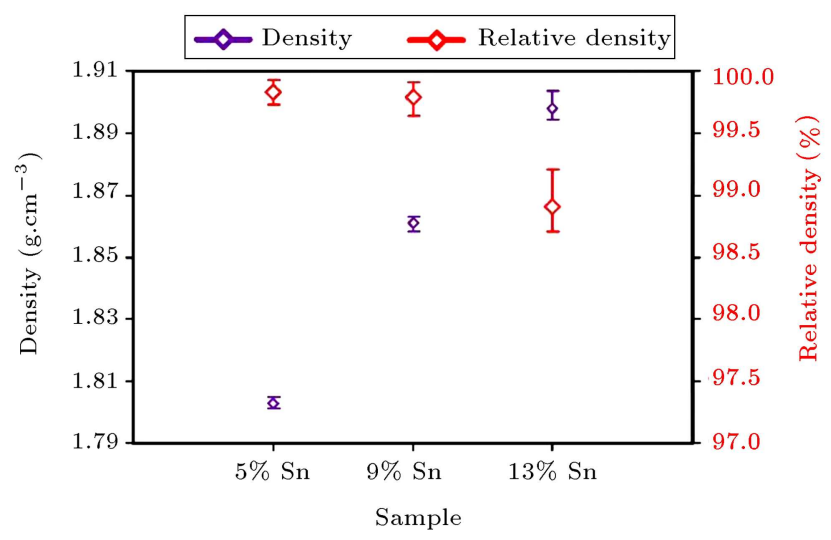

Figure 5. Achieved density and relative density values of the alloys produced. 


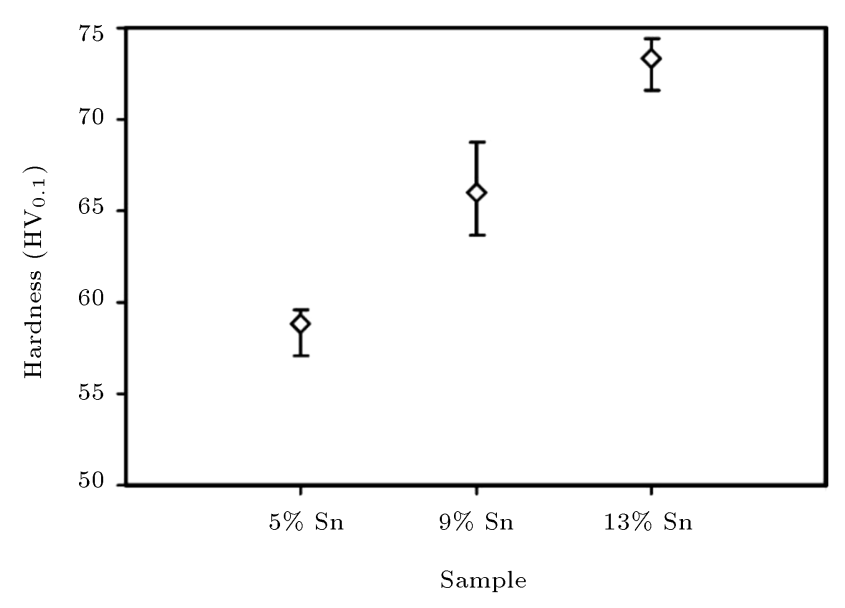

Figure 6. Hardness values of the alloys produced.

$13 \%$ Sn. Moreover, Liu et al. [43] reported that the hardness increased with the increasing Sn ratio. Turan et al. reported that pure magnesium with a relative density of $99.76 \%$, produced by hot pressing, had an average hardness value of $40.2 \mathrm{HV}$ [55]. In the present study, the sample hardness with $5 \% \mathrm{Sn}$ is $58.8 \mathrm{HV}_{(0.1)}$, which is $46.26 \%$ higher than pure $\mathrm{Mg}$. Liu et al. [43] calculated the hardness of the samples produced by casting according to the formula $\mathrm{HV}_{(0.01)}=50.77 \mathrm{w}^{0.17}$ ( $w$ is Sn content by weight in formula). According to this calculation, they found the hardness of the sample with $10 \%$ Sn produced by casting as approximately $75 \mathrm{HV}_{(0.01)}$. According to this formula, the hardness of the sample with $13 \% \mathrm{Sn}$ was calculated as 78.5 $\mathrm{HV}$ in the present study. However, the hardness value determined experimentally was $73.3 \mathrm{HV}_{(0.1)}$ on average. This obtained hardness value is $82.33 \%$ higher than the hardness of pure $\mathrm{Mg}$.

Figure 7 shows the average stress-strain curves obtained from the tensile testing of the materials produced. Since the addition of Sn improves hardness, it increases strength values, too. However, the elongation

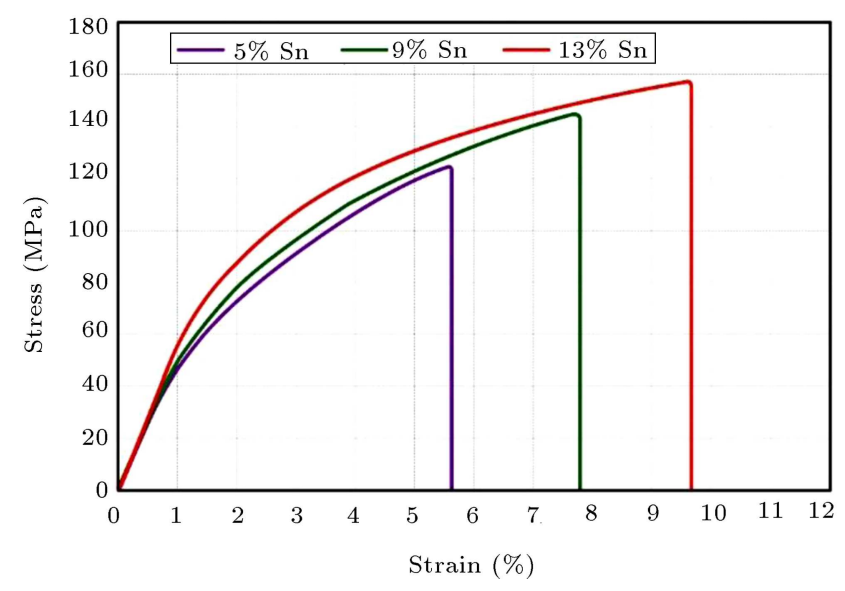

Figure 7. Stress-strain curves obtained from the tensile testing of the alloys produced. values obtained with the increasing $\mathrm{Sn}$ ratio have also increased. As a result of the tensile testing applied to the samples produced by the casting method with the addition of Sn between $1-10 \%$ by weight at varying ratios, Liu et al. [43] found that both tensile strength and ductility increased together until the addition of $\mathrm{Sn}$ reached 5\%. Unlike Liu et al., the $\mathrm{Sn}$ ratios above $5 \%$ also increased ductility in the present study. This difference is attributed to the microstructure properties that have been provided by the production methods, used in the two studies. In the explanations about the SEM elemental mapping analysis, $\mathrm{Mg}$-Sn alloys produced by the casting method have been reported to be consisting of a continuous $\mathrm{Mg}_{2} \mathrm{Sn}$ film at grain boundaries. Liu et al. [43] reported that the tendency of the $\mathrm{Mg}_{2} \mathrm{Sn}$ phase to form a semi-continuous network at grain boundaries increased with increasing $\mathrm{Sn}$ content. These large intermetallic phases and semicontinuous network morphology have been reported to adversely affect strength and ductility by accelerating crack formation and progression [43]. Since the $\mathrm{Mg}_{2} \mathrm{Sn}$ phase in the present study formed as discrete particles at the grain boundaries, it increased the ductility and strength. Liu et al. [43] obtained tensile strengths of about $120 \mathrm{MPa}$ and elongation values close to $8 \%$ at the materials to which they added $5 \% \mathrm{Sn}$. In the present study, the average tensile strength value of $125.18 \mathrm{MP}$ and an average elongation value of $5.63 \%$ were obtained in the sample with $5 \% \mathrm{Sn}$. The average tensile strength obtained with the increase of $13 \%$ of $\mathrm{Sn}$ was $157.2 \mathrm{MPa}$ and elongation was $9.68 \%$. According to the Hall-Petch rule, one effective way to increase strength in materials is to reduce the grain size [56]. Based on the SEM analyses, it was revealed that the average grain sizes obtained in the present study were much smaller than the grain size of the cast $\mathrm{Mg}-\mathrm{Sn}$ alloys. It was thought that the difference between the strength values found in the study by Liu et al. [43] and the strength values present in the present study resulted from the morphology of the precipitates formed in the microstructure and the grain size. The hardness, strength, and ductility values of Mg-Sn alloys produced, as well as their comparison with literature data, are given in Table 1 . Some properties of pure $\mathrm{Mg}$ and cast $\mathrm{Mg}-\mathrm{Sn}$ alloys are approximate values as they were taken from the graphs shown in the references.

Figure 8 shows the SEM images taken of the fracture surfaces of the samples after the tensile testing. There is no porosity in the fracture surface images as in the SEM images, shown in Figure 3. Compared with the fracture surfaces, it is seen that a more ductile fracture surface is obtained with the increasing $\mathrm{Sn}$ ratio in accordance with the ductility values determined by the tensile tests. In particular cases of $9 \%$ and $13 \%$ Sn added to the samples, an 
Table 1. Mechanical properties of alloys produced by $\mathrm{P} / \mathrm{M}$ and similar alloys produced by casting.

\begin{tabular}{lcccc}
\hline Material & $\begin{array}{c}\text { Hardness } \\
\text { (HV) }\end{array}$ & $\begin{array}{c}\text { Yield } \\
\text { strength } \\
\text { (MPa) }\end{array}$ & $\begin{array}{c}\text { Tensile } \\
\text { strength } \\
\text { (MPa) }\end{array}$ & $\begin{array}{c}\text { Elongation } \\
\text { (\%) }\end{array}$ \\
\hline P/M Mg-5 wt.\% Sn & 58.8 & 53.42 & 125.18 & 5.63 \\
P/M Mg-9 wt.\% Sn & 65.96 & 60.12 & 144.65 & 7.79 \\
P/M Mg-13 wt.\% Sn & 73.3 & 75.81 & 157.2 & 9.68 \\
Cast Mg (pure) & $40[43]$ & $24[58]$ & $86[58]$ & $4.8[58]$ \\
Cast Mg-5 wt.\% Sn & $66.74[43]$ & $30[57]$ & $120[43]$ & $7.8[43]$ \\
Cast Mg-10 wt.\% Sn & $75.09[43]$ & - & $95[43]$ & $3.3[43]$ \\
\hline
\end{tabular}
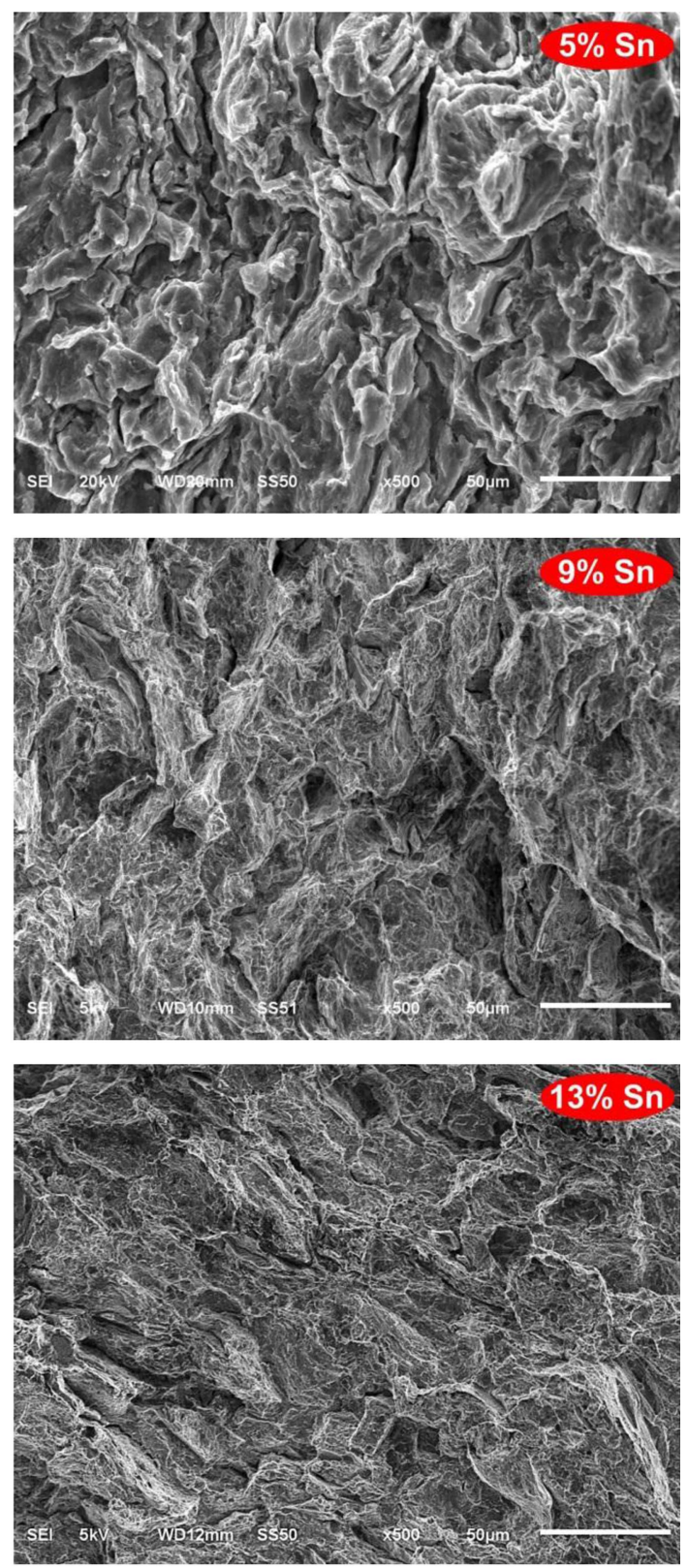

Figure 8. SEM images taken of the fracture surfaces after tensile testing. abundant amount of dimple formation draws much attention. Nevertheless, the breakage occurred from inside the grains in all the components.

\section{Conclusions}

In this study, Mg-Sn alloys with different Sn contents were produced by the $\mathrm{P} / \mathrm{M}$ method by a new mixing technique to avoid the problems caused by high reactivity of $\mathrm{Mg}$. The following results were drawn from the characterization of the microstructure and mechanical properties of the alloys produced:

- The XRD analysis showed that the microstructure was composed of $\alpha-\mathrm{Mg}$ and $\mathrm{Mg}_{2} \mathrm{Sn}$ phases and, with increasing $\mathrm{Sn}$ ratio, the intensity of $\alpha-\mathrm{Mg}$ peaks decreased and the intensity of $\mathrm{Mg}_{2} \mathrm{Sn}$ phase peaks increased;

- The SEM examinations showed that microstructures were composed of coaxial and finer grains, compared to the casting methods. The increasing Sn content increased the volume fraction of the $\mathrm{Mg}_{2} \mathrm{Sn}$ phase, thereby ensuring a finer grain microstructure;

- Higher hardness values were obtained due to the formation of more $\mathrm{Mg}_{2} \mathrm{Sn}$ precipitates with increasing Sn content;

- As the Sn content increased, the volume ratio of the $\mathrm{Mg}_{2} \mathrm{Sn}$ precipitates increased, and depending on the refined grain size, the yield and tensile strengths increased. Contrary to $\mathrm{Mg}$-Sn alloys produced by the casting method, the increase of Sn content over 5\% increased the ductility. This condition is attributed to the morphology of the resulting $\mathrm{Mg}_{2} \mathrm{Sn}$ phase. While the $\mathrm{Mg}_{2} \mathrm{Sn}$ phase that was formed as a continuous and coarse network at the grain boundaries decreased the strength and ductility as the $\mathrm{Sn}$ ratio increased in the parts produced by casting, in the present study, strength and ductility increased together due to the discrete $\mathrm{Mg}_{2} \mathrm{Sn}$ precipitates with a blocky morphology formed at grain boundaries due to $\mathrm{P} / \mathrm{M}$; 
- So far, P/M has been considered to be a difficult method for the production of $\mathrm{Mg}$ and its alloy parts because of the high reactivity of $\mathrm{Mg}$ powders, although it offers many advantages such as the microstructure consisting of fine and coaxial grains, superior mechanical properties, and the ability to increase the flexibility of the alloy system in comparison to the casting techniques. The mixing technique applied in the present study provided difficulties and problems, caused by the high reactivity of $\mathrm{Mg}$ powders to be avoided. The results obtained from the characterization of microstructure and mechanical properties showed that the mixing technique was successful. Given the superior properties of the produced components, it can be concluded that $\mathrm{P} / \mathrm{M}$ is a promising method for the production of $\mathrm{Mg}$ alloys with similar innovations or modifications to the current work.

\section{Acknowledgement}

This study was supported by Bingol University Scientific Research Projects Coordination Unit with the BAP-MMF.2017.00.007 project number. We would like to express our gratitude to the staff of the BUSRP unit and the staff of the Central Laboratory of Bingol University for their interest in the study and their efforts.

\section{References}

1. Polmear, I.J. "Overview magnesium alloys and applications", Materials Science and Technology, 10(1), pp. 1-16 (1994).

2. Kojima, Y. "Platform science and technology for advanced magnesium alloys", Materials Science Forum, 350(351), pp. 3-18 (2000).

3. Lloyd, DJ. "Particle reinforced aluminium and magnesium matrix composites", International Materials Reviews, 39(1), pp. 1-23 (1994).

4. Lindroos, V.K. and Talvitie, MJ. "Recent advances in metal matrix composites", Journal of Materials Processing Technology, 53(1-2), pp. 273-284 (1995).

5. Ohara, H. "Magnesium alloys and their application", Light Metals, 48(8), pp. 422-424 (1998).

6. Avedesian M.M. and Baker, H., ASM Specialty Handbook: Magnesium and Magnesium Alloys, ASM International, Materials Park, OH (1999).

7. Fukuda, H., Szpunar, J.A., Kondoh, K., and Chromik, R. "The influence of carbon nanotubes on the corrosion behaviour of AZ31B magnesium alloy", Corrosion Science, 52(12), pp. 3917-3923 (2010).

8. Changizian, P., Zarei-Hanzaki, A. and Roostaei, A.A., "The high temperature flow behaviour modelling of AZ81 magnesium alloy considering strain effects", Materials \& Design, 39, pp. 384-389 (2012).
9. Yong, M.S. and Clegg, A.J. "Process optimisation for a squeeze cast magnesium alloy", Journal of Materials Processing Technology, 145(1), pp. 134-141 (2004).

10. Dobrzański, L.A., Tański, T., Č ıžek, L. and Domagała, J. "Mechanical properties and wear resistance of magnesium casting alloys", Journal of Achievements in Materials and Manufacturing Engineering, 31(1), pp. 83-90 (2008).

11. Liu, L. and Dong, C. "Gas tungsten-arc filler welding of AZ31 magnesium alloy", Materials Letters, 60(1718), pp. 2194-2197 (2006).

12. Chai, S., Zhang, D., Pan, F., Dong, J., Guo, F., and Dong, Y. "Influence of post-weld hot rolling on the microstructure and mechanical properties of AZ31 magnesium alloy sheet", Materials Science and Engineering: A, 588, pp. 208-213 (2013).

13. Sabetghadam-Isfahani, A., Zalaghi, H., Hashempour, S., Fattahi, M., Amirkhanlou, S., and Fattahi, Y. "Fabrication and properties of $\mathrm{ZrO} 2 / \mathrm{AZ} 31$ nanocomposite fillers of gas tungsten arc welding by accumulative roll bonding", Archives of Civil and Mechanical Engineering, 16(3), pp. 397-402 (2016).

14. Kuwahara, H., Al-Abdullat, Y., Ohta, M., Tsutsumi, S., Ikeuchi, K., Mazaki, N., and Aizauta, T. "Surface reaction of magnesium in hank's solutions", Materials Science Forum, 350(351), pp. 349-358 (2000).

15. Gray, J.E. and Luan, B. "Protective coatings on magnesium and its alloys-a critical review", Journal of Alloys and Compounds, 336(1-2), pp. 88-113 (2002).

16. Dahle, A.K., St John, D.H., and Dunlop, G.L. "Developments and challenges in the utilisation of magnesium alloys", Materials Forum, 24, pp. 167-182 (2000).

17. Luo, A.A. "Magnesium casting technology for structural applications", Journal of Magnesium Alloys, 1(1), pp. 2-22 (2013).

18. Luo, A. and Pekguleryuz, M.O. "Review cast magnesium alloys for elevated temperature applications", Journal of Materials Science, 29(20), pp. 5259-5271 (1994).

19. Luo, A.A. "Recent magnesium alloy development for elevated temperature applications", International $M a$ terials Reviews, 49(1), pp. 13-30 (2004).

20. Haferkamp, H., Boehm, R., Holzkamp, U., Jaschik, C., Kaese, V., and Niemeyer, M. "Alloy development, processing and applications in magnesium lithium alloys", Materials Transaction, 42, pp. 1160-1166 (2001).

21. Perez, P., Garces, G., and Adeva, P. "Influence of texture on the mechanical properties of commercially pure magnesium prepared by powder metallurgy", Journal of Materials Science, 42(11), pp. 3969-3976 (2007).

22. Sannes, S. and Westengen, H. "Magnesium Alloys and Their Applications", In Magnesium Alloys and Their Applications, B.L. Mordike, K.U. Kainer, Eds., pp. 223-228, Werkstoff-Informationsgesellschaft, Frankfurt (1998). 
23. Dahle, A.K., Lee, Y.C., Nave, M.D., Schaffer, P.L., and St John, D.H. "Development of the as-cast microstructure in magnesium-aluminium alloys", Journal of Light Metals, 1(1), pp. 61-72 (2001).

24. Munitz, A., Cotler, C., Stern, A., and Kohn, G. "Mechanical properties and microstructure of gas tungsten arc welded magnesium AZ91D plates", Materials Science and Engineering: A, 302(1), pp. 68-73 (2001).

25. Bolen, J., Letzig, D., and Kainer, K.U. "New perspectives for wrought magnesium alloys", Materials Science Forum, 546(549), pp. 1-10 (2007).

26. Agnew, S.R. "Wrought magnesium: A 21st century outlook", JOM, 56, pp. 20-21 (2004).

27. Watari, H., Davey, K., Rasgado, M.T., Hoga, T., and Izawa, S. "Semi solid manufacturing process of magnesium alloys by twin-roll casting", Journal of Materials Processing Technology, 155(156), pp. 16621667 (2004).

28. Kulekci, M.K. "Magnesium and its alloys applications in automotive industry", The International Journal of Advanced Manufacturing Technology, 39(9-10), pp. 851-865 (2008).

29. Mordike, B.L. and Ebert, T. "Magnesium: Propertiesapplications-potential", Materials Science and Engineering: A, 302(1), pp. 37-45 (2001).

30. German, R.M., Powder Metallurgy and Particulate Materials Processing, Metal Powder Industries Federation, Princeton (2005).

31. Gökçe, A., Fındık, F. and Kurt, A.O. "Microstructural examination and properties of premixed Al-Cu-Mg powder metallurgy alloy", Materials Characterization, 62(7), pp. 730-735 (2011).

32. Sims, C.T., Stolof, N.S., and Hagel, W.C., Superalloys II, Wiley-Interscience Publication, New York (1987).

33. Pollock, T.M. and Tin, S. "Nickel-based superalloys for advanced turbine engines: Chemistry, microstructure and properties", Journal of Propulsion and Power, 22(2), pp. 361-374 (2006).

34. Stoloff, N.S. "Wrought and powder metallurgy (P/M) superalloys", In ASM Handbook: Properties and Selection: Irons, Steels, and High Performance Alloys, pp. 1478-1527, ASM International, Materials Park, OH (2005).

35. Simchi, A. "Densification and microstructural evolution during co-sintering of Ni-base superalloy powders", Metallurgical and Materials Transaction A, 37(8), pp. 2549-2557 (2006).

36. Vervoort, P.J., Vetter, R., and Duszczyk, J. "Overview of powder injection molding", Advanced Performance Materials, 3(2), pp. 121-151 (1996).

37. Rashad, M., Pan, F., and Asif, M. "Room temperature mechanical properties of $\mathrm{Mg}-\mathrm{Cu}-\mathrm{Al}$ alloys synthesized using powder metallurgy method", Materials Science and Engineering: A, 644, pp. 129-136 (2015).
38. Han, B.Q. and Dunand, D.C. "Microstructure and mechanical properties of magnesium containing high volume fractions of yttria dispersoids", Materials Science and Engineering: A, 277(1-2), pp. 297-304 (2000).

39. Lei, T., Tang, W., Cai, S.H., Feng, F.F., and Li, N.F. "On the corrosion behaviour of newly developed biodegradable $\mathrm{Mg}$-based metal matrix composites produced by in situ reaction", Corrosion Science, 54, pp. 270-277 (2012).

40. Wolf, M., Luczak, M., Schaper, J.G., Wiese, B., Dahms, M., Ebel, T., Willumeit-Rimer, R., and Klassen, T. "In vitro biodegradation testing of $\mathrm{Mg}$ alloy EZK400 and manufacturing of implant prototypes using PM (powder metallurgy) methods", Bioactive Materials, 3, pp. 213-217 (2018).

41. Medina, J., Pérez, P., Garcés, G., Stark, A., Schell, N., and Adeva, P. "High-strength Mg-6Zn-1Y-1Ca (wt\%) alloy containing quasicrystalline I-phase processed by a powder metallurgy route", Materials Science and Engineering A, 715, pp. 92-100 (2018).

42. Turan, M.E., Sun, Y., and Akgul, Y. "Mechanical, tribological and corrosion properties of fullerene reinforced magnesium matrix composites fabricated by semi powder metallurgy", Journal of Alloys and Compounds, 740, pp. 1149-1158 (2018).

43. Liu, H., Chen, Y., Tang, Y., Wei, S., and Niu, G. "The microstructure, tensile properties and creep behaviour of as-cast Mg-(1-10)\%Sn alloys", Journal of Alloys and Compounds, 440(1-2), pp. 122-126 (2007).

44. Kozlov, A., Ohno, M., Leil, T.A., Hort, N., Kainer, K.U., and Schmid-Fetzer, R. "Phase equilibria, thermodynamics and solidification microstructures of $\mathrm{Mg}$ Sn-Ca alloys. Part 2: Prediction of phase formation in Mg-rich Mg-Sn-Ca cast alloys", Intermetallics, 16(2), pp. 316-321 (2008).

45. Cheng, W.L., Park, S.S., You, B.S., and Koo, B.H. "Microstructure and mechanical properties of binary Mg-Sn alloys subjected to indirect extrusion", Materials Science and Engineering: A, 527(18-19), pp. 46504653 (2010).

46. Özgün, Ö., Gülsoy, H.Ö., Yilmaz, R., and Findik, F. "Injection molding of nickel based 625 superalloy: Sintering, heat treatment, microstructure and mechanical properties", Journal of Alloys and Compounds, 546, pp. 192-207 (2013).

47. Özgün, Ö., Gülsoy, H.Ö., Yilmaz, R., and Findik, F. "Microstructural and mechanical characterization of injection molded 718 superalloy powders", Journal of Alloys and Compounds, 576, pp. 140-153 (2013).

48. Gülsoy, H.Ö., Özgün, Ö., and Bilketay, S. "Powder injection molding of Stellite 6 powder: Sintering, microstructural and mechanical properties", Materials Science and Engineering: A, 651, pp. 914-924 (2016).

49. ÖZgün, Ö. and Dinler, İ. "Production and Characterization of WC-reinforced Co-based superalloy matrix composites", Metallurgical and Materials Transactions A, 49(7), 2977-2989 (2018). 
50. Liu, X., Shan, D., Song, Y., Chen, R., and Han, E. "Influences of the quantity of $\mathrm{Mg}_{2} \mathrm{Sn}$ phase on the corrosion behaviour of Mg-7Sn magnesium alloy", Electrochimica Acta, 56(5), pp. 2582-2590 (2011).

51. Chen, D., Ren, Y.P., Guo, Y., Pei, W.L., Zhao, H.D., and Qin, G.W. "Microstructures and tensile properties of as-extruded Mg-Sn binary alloys", Transactions of Nonferrous Metals Society of China, 20(7), pp. 13211325 (2010).

52. Erickson, G.L. "Polycrystalline cast superalloys", In ASM Handbook: Properties and Selection: Irons, Steels, and High Performance Alloys, pp. 1528-1550, ASM International, Materials Park, OH (2005).

53. Mitchell, R.J., Rae, C.M.F., and Tin, S. "Grain boundary transformations during isothermal exposure of powder metallurgy nickel base superalloys for turbine disc applications", Materials Science and Technology, 21(1), pp. 125-132 (2005).

54. Sundararaman, M. "The role of refractory metal additions in precipitation processes in superalloys", Mineral Processing and Extractive Metallurgy Review, 22(2), pp. 681-700 (2002).

55. Turan, M.E., Sun, Y., Akgul, Y., Turen, Y., and Ahlatci, H. "The effect of GNPs on wear and corrosion behaviors of püre magnesium", Journal of Alloys and Compounds, 724, pp. 14-23 (2017).

56. Kim, H.K., Lee, Y.I., and Chung, C.S. "Fatigue properties of a fine-grained magnesium alloy produced by equal channel angular pressing", Scripta Materialia, 52(6), pp. 473-477 (2005).

57. Liu, H., Chen, Y., Zhao, H., Wei, S., and Gao, W. "Effects of strontium on microstructure and mechanical properties of as-cast Mg-5wt.\%Sn alloy", Journal of Alloys and Compounds, 504(2), pp. 345-350 (2010).

58. Sun, H.F., Li, C.J., Xie, Y., and Fang, W.B. "Microstructures and mechanical properties of pure mag- nesium bars by high ratio extrusion and its subsequent annealing treatment", Transactions of Nonferrous Metals Society of China, 22(2), pp. 445-449 (2012).

\section{Biographies}

Özgür Özgün is an academician at the Department of Mechanical Engineering in Bingol University. He received MS and $\mathrm{PhD}$ degrees from Sakarya University at the Department of Metal Education in 2003 and 2007, respectively. His research interests are materials science, powder metallurgy, superalloys, and composite materials.

Kubilay Aslantaş is a Professor with tenure at the Department of Mechanical Engineering. He received BS and PhD degrees (in 2003) in Mechanical Education from Gazi University. Dr. Aslantas has previously worked as a Visiting Scholar in Mechanical Science and Engineering at the University of Illinois UrbanaChampaign. His research interests are micromachining, modeling of machining, cutting of natural stones, fatigue, and fracture.

Ali Erçetin is a Research Assistant at the Department of Mechanical Engineering of Bingol University. He completed his undergraduate education at the Department of Mechanical Engineering from Uşak University. He also received an MS in Mechanical Engineering from Afyon Kocatepe University in 2015. He has been committed to his PhD education in Mechanical Engineering from Afyon Kocatepe University since 2015. His research interests include micro machining, high-speed machining, powder metallurgy, composite materials, heat treatment, and material characterization. 